Portland State University

PDXScholar

\title{
Student-Perceived Quality of Motivational Interviewing Training: A Factor-Analytic Study
}

\author{
Douglas Smith \\ University of Illinois at Urbana-Champaign \\ Melinda Hohman \\ San Diego State University \\ Stéphanie Wahab \\ Portland State University, wahabs@pdx.edu \\ Trevor Manthey \\ George Washington University
}

Follow this and additional works at: https://pdxscholar.library.pdx.edu/socwork_fac

Part of the Social Work Commons

Let us know how access to this document benefits you.

\section{Citation Details}

Douglas Smith, Melinda Hohman, Stéphanie Wahab, and Trevor Manthey, "Student-Perceived Quality of Motivational Interviewing Training: A Factor-Analytic Study," Journal of the Society for Social Work and Research 8, no. 1 (Spring 2017): 1-18.

This Article is brought to you for free and open access. It has been accepted for inclusion in School of Social Work Faculty Publications and Presentations by an authorized administrator of PDXScholar. Please contact us if we can make this document more accessible: pdxscholar@pdx.edu. 


\title{
Student-Perceived Quality of Motivational Interviewing Training: A Factor-Analytic Study
}

\author{
Douglas Smith University of Mlinois at Urbana-Champaign \\ Melinda Hohman San Diego State University \\ Stéphanie Wahab Portland State University \\ Trevor Manthey George Washington University
}

\begin{abstract}
Objective: This study developed and tested a student-report measure of motivational interviewing (MI) teaching quality called the Evaluation of Motivational Interviewing Teaching (EMIT) scale. Method: Social work students $(N=297)$ receiving course content on motivational interviewing completed the EMIT, and exploratory factor analysis investigated whether theory-based dimensions of teaching emerged as EMIT subscales, including: interactivity/skill building, MI content coverage, modeling MI during teaching, trainee autonomy violation, and encouraging ongoing training in MI. Results: Two subscales emerged representing MIconsistent (28 items, $\alpha=.92$ ) and MI-inconsistent teaching practices (7 items, $\alpha=.73$ ). Conclusions: Although more research is needed on the EMIT, this study supports the initial reliability of the instrument and can help social work educators evaluate MI teaching quality.
\end{abstract}

KEYWORDS: motivational interviewing, teaching, evidence-based practice, factor analysis

doi: $10.1086 / 690636$

M otivational interviewing (MI) is a strengths-based, client-centered, directive way of structuring conversations about change (Manthey, Knowles, Asher, \& Wahab, 2011; Wahab, 2005). Miller and Rollnick (2013) describe MI as a "collaborative, goal oriented style of communication with particular attention to the language of change. It is designed to strengthen personal motivation for and commitment to a specific goal by eliciting and exploring the person's own reasons for change within an atmosphere of acceptance and compassion" (p. 29). MI originated in the 1980s in the substance-use field and has since spread to a wide variety of substance-use, health, mental health, criminal justice, and education venues (Miller \& Rollnick, 2013). MI is designated as an evidence-based practice, with more than 300 peer-reviewed articles analyzing outcomes (Miller \& Rollnick, 2013).

Journal of the Society for Social Work and Research, Volume 8, Number 1. 2334-2315/2017/0801-0001/\$10.00. (C) 2017 by the Society for Social Work and Research. All rights reserved. 
Training in specific empirically supported treatments is generally lacking in social work (Smith, 2012). However, schools of social work have begun to offer MI in their curricula, either embedded in practice courses or as stand-alone courses (Hohman, Pierce, \& Barnett, 2015). This is in response to MI's growing evidence, use, and demand among employers, funders, and some state regulators (Miller, Forcehimes, \& Zweben, 2011). MI fits well with social work values (Hohman, 2012; Manthey, Knowles, et al., 2011), and training in MI provides students with concrete tools for engaging clients in an empathic manner and the ability to use a researchinformed practice. Thus, MI training meets both required competencies for accredited social work programs (Council on Social Work Education, 2015).

As the evidence supporting MI has increased over time so has the demand for MI teaching and implementation support. Researchers, employers, and practitioners need to be able to define and measure what constitutes best teaching practices. Such efforts may improve the quality of MI training and aid the dissemination of this empirically supported treatment while safeguarding fidelity to the model. The purpose of this study was to develop and test a measure of student-reported MI training competency called the Evaluation of Motivational Interviewing Teaching (EMIT).

\section{Why Focus on Best Practices in Teaching MI?}

MI involves a complex skill set, and although some of the principles and skills may seem simple, they are complicated to learn in practice (Manthey, Jackson, \& EvansBrown, 2011; Miller \& Rollnick, 2013). Many employers and practitioners who have sought to learn MI have underestimated how much practice and follow-up learning MI requires (e.g., Forsberg, Ernst, \& Farbring, 2011). For example, Miller and Rollnick (2009) quipped that when they had been invited to give MI presentations over the lunch hour, it gave them the impression that practitioners thought MI could be quickly taught over pizza.

Therefore, obtaining a better understanding of teaching processes is very important, as it reduces the potential for dissemination of an intervention that is not really MI. For example, some practitioners claimed to be conducting MI when, in reality, they were not (Miller \& Rollnick, 2009). Many substance-use treatment providers indicate that they are using MI principles in practice (Gifford et al., 2012), and it seems unlikely that practice-as-usual settings provide the MI intervention in its entirety and with high fidelity (Santa Ana et al., 2008). For example, professionals in the field overestimate their MI skills when their self-reported MI skills are compared to neutral expert ratings of their skills (Wain et al., 2015). Similarly, some research studies nominally of MI have included interventions not recognizable as MI (Miller \& Rollnick, 2013), potentially skewing findings from metaanalyses on the effectiveness of MI studies. Fortunately, there are validated observational assessment instruments that can be used to determine if MI is actually 
being delivered in practice and research (Moyers, Martin, Manual, Miller, \& Ernst, 2010).

Although we can reasonably detect when the MI intervention is delivered with fidelity, there currently is no reliable and valid instrument available to determine MI teaching quality. Having access to teachers who are accurately and effectively teaching MI (Miller \& Moyers, 2006; Söderlund, Madson, Rubak, \& Nilsen, 2011) has been forwarded as an important means of disseminating MI. Additionally, Madson, Lane, and Noble (2012) have stressed the necessity for evaluating the quality of MI teaching. Madson, Campbell, Barrett, Brondino, and Melchert (2005) note that we need to know how a provider was trained in MI as an initial dissemination safeguard. In short, having a reliable and valid measure of MI training is important for the effective dissemination of MI.

\section{The Maturity of Research on MI Teaching and Dissemination of MI}

What, then, should constitute high quality MI teaching or an effective teacher? Following, we review the literature on MI skills acquisition and discuss current dissemination efforts for MI. As we review the research and current MI dissemination efforts, we make connections to the development of our proposed five-dimension model of MI teaching, which is summarized in Table 1 . These dimensions include

1. interactivity/skill-building,

2. modeling MI during training,

3. supporting students' autonomy,

4. encouraging ongoing training in MI, and

5. providing up-to-date content regarding MI.

It is with these dimensions in mind that we developed the item pool for the EMIT scales.

Research and theory-based dimensions of $\mathrm{MI}$ teaching. For MI there is perhaps more literature on which teaching practices are associated with skills acquisition than for any other psychosocial intervention. Madson, Loignon, and Lance's (2009) review identified 28 studies on teaching outcomes. One major finding on MI teaching is that self-directed learning through reading books and self-reflection doesn't appear to be an effective strategy for learning MI (Decker \& Martino, 2013; Miller, Yahne, Moyers, Martinez, \& Pirritano, 2004). Furthermore, attending workshops alone seems to produce positive but limited and temporary outcomes (Baer et al., 2004; Roten, Zimmermann, Ortega, \& Despland, 2013; Walters, Matson, Baer, \& Ziedonis, 2005). Self-paced or informational-only teaching models can be contrasted with longer, more interactive training. Interactive training differs from self-paced and informational-only teaching by providing skill-building exercises (i.e., EMIT's first dimension) such as role-play activities followed by interactive debriefings. Sec- 
Table 1

Five Proposed Dimensions of Teaching Motivational Interviewing (MI)

Subscale Description

1. Interactivity/Skill Accurately learning about how to play a piano doesn't mean someone Building can actually play a piano. Providing evocative and interactive practice activities is highly valued by the Motivational Interviewing Network of Trainers (MINT) and appears to be a foundational component of effective MI training.

2. Modeling MI Skills A competent teacher of MI should excel at delivering MI themselves During Training and use MI skills when facilitating classes.

3. Trainee Autonomy Instead of convincing or mandating students about the virtues of MI Violation (i.e., autonomy violation), MI teachers should emphasize student autonomy and recognize the limitations of MI. Validating that students can choose to completely disregard or use only portions of MI once the course is over is important. This dimension is similar to modeling MI, but rather than just modeling the technical skills (i.e., reflections, affirmations) teachers are modeling autonomy support for students to decide whether or not to use MI.

4. Encouragement of Learning MI appears to be an ongoing process rather than a one-time Ongoing Training event. Developing MI skill takes time, and it is important that MI teachers emphasize the importance of ongoing practice, training, and feedback in order to sustain and improve skills.

5. MI Content

It is important that MI teachers accurately present what MI is. Due to rapid dissemination, some teachers have presented MI inaccurately or have taught MI using outdated concepts and ignoring important new developments.

Note. These five dimensions correspond to our hypotheses about subscales that will emerge in this study's exploratory factor analysis for our measure, the Evaluation of MI Teaching Scale (EMIT).

ond, trainers/teachers are encouraged to model and demonstrate MI throughout the teaching process (i.e., EMIT's second proposed dimension). The importance of this teaching strategy was articulated in the second edition of the book Motivational Interviewing: Preparing People for Change:

The skills and qualities of motivational interviewing can be demonstrated by the very manner in which you deal with your trainees. There is a certain integrity to showing, in your own training manner, the very style you wish to impart. (Miller \& Rollnick, 2002, pp. 186-187)

Knowing whether instructors are modeling the intervention may say something about their expertise in the intervention and the quality of the teaching they pro- 
vide. To date, there is no research on whether modeling MI skills or providing interactive trainings is associated with better teaching outcomes. To further that research we must first know if we can measure differences in interactivity and MI modeling during MI teaching.

Consequently, Hohman (2012) proposed a teaching model based on a MI method introduced by Miller and Rollnick (2002) called EPE-Elicit, Provide, Elicit. In this model, the trainer/teacher elicits students' current knowledge, skills, values, and goals in providing effective practice to build on the knowledge they possess. The trainer/teacher then provides MI content and models MI skills throughout using reflective listening, open-ended questions, affirmations, and summaries of the class discussion. The trainer/teacher provides MI demonstrations and opportunities for students to practice skills in a supportive setting. The instructor also provides practice feedback through coaching in a manner that is MI-consistent. Trainers/teachers also model for students how to handle discord or reluctance when it arises, again using MI methods of dancing with discord (Wells, Jones, \& Jones, 2014). This is a subcomponent of modeling MI for trainers, which we attempted to measure as a third dimension on the EMIT called Trainee Autonomy Violation. It is differentiated from modeling other MI skills (i.e., reflections, open questions, affirmations) with trainees in that it specifically deals with the phenomenon of addressing trainee ambivalence toward using MI. Just as practitioners of MI are taught to not directly confront clients or attempt to persuade them to change, trainers also are taught to respect trainee ambivalence toward learning a new model. (For an excellent sample dialogue of responding to trainee ambivalence in an MI-consistent manner, see Rosengren [2009, p. 7].) Finally, the trainer/teacher elicits students' thoughts, questions, and application ideas. Elicitation also should include feedback about the training itself.

Based on the MI teaching research, there also is emerging consensus that retaining MI skills doesn't seem to occur without some form of added ongoing supervision, fidelity assessment, and/or coaching (Bennett et al., 2007; Forsberg, Forsberg, Lindqvist, \& Helgason, 2010; Heaven, Clegg, \& Maguire, 2006; Madson et al., 2009; Miller et al., 2004; Mitcheson, Bhavsar, \& McCambridge, 2009; Moyers et al., 2008). Use of observational coding by an experienced MI trainer usually aids such coaching. Access to ongoing training is particularly important because many individuals tend to overestimate their MI skills; they report that they have learned and retained MI skills, but evaluation of their practice suggests a different story (Miller \& Mount, 2001; Wain et al., 2015). Thus, the fourth proposed dimension of MI teaching is the extent to which a teacher encourages ongoing training and learning in MI.

Finally, perhaps the most basic way of knowing whether someone received quality MI training is knowing if they received adequate content coverage of the intervention, and knowing the extent to which they did not receive misinformation. Thus, the fifth proposed dimension for the EMIT instrument attends to MI content 
coverage during training. Miller and Moyers' (2006) eight stages of learning MI offer some clues to better understanding the efficacy of MI training, including: (a) openness to collaboration with clients' own expertise; (b) proficiency in clientcentered counseling, including accurate empathy; (c) recognition of key aspects of client speech that guide the practice of MI; (d) eliciting and strengthening client change talk; (e) rolling with resistance (now referred to as dancing with discord); (f) negotiating change plans; (g) consolidating client commitment; and (h) switching flexibly between MI and other intervention styles. Miller and Rollnick (2013) recently added to this list the use of the four processes (engage, focus, evoke, and plan). Thus, MI teaching should seemingly include emphasis of these concepts. Further, instruction should include content about what MI is not. For example, Miller and Rollnick (2009) articulated that MI should not be confused with a trick to get clients to do what you want them to do, or with a decisional-balance activity. Regarding the latter, MI is more focused on eliciting change talk, or pro-change language uttered by clients during MI sessions. A decisional balance activity also elicits sustain talk, or pro-status-quo language, which is associated with less change at follow up (Magill et al., 2014).

Research on $\mathrm{Ml}$ teachers' attitudes toward $\mathrm{MI}$ training. In addition to a growing literature on training practices, there exists an organization dedicated to promoting best practice standards in training individuals on MI, the Motivational Interviewing Network of Trainers (MINT). Here we describe the initial efforts of MINT to define and measure components of quality MI education and past research surveying MINT members and others who provide MI instruction.

Interestingly, MINT does not yet have a certification process for evaluating MI teaching competency. There are, however, initial efforts within MINT to develop an observation measure of trainer effectiveness, which ultimately could be used by experienced trainers or coders to code training effectiveness in MI (MINT Forum, 2014). The EMIT, developed in this study, will supplement these efforts by providing a student-report measure, which will have the benefit of a lower administrative burden.

Madson, Lane, and Noble (2012) conducted a mixed-method survey of 92 MINT members to elicit important factors and processes related to providing quality MI training. Trainers in this study reported using training methods that included role plays, group exercises, group discussions, modeling, videos, and demonstrations. Although this study underscores the proposed dimensions of training that we attempt to measure with the EMIT-particularly the interactivity/skill-building and modeling constructs - this study focused only on the extent to which MI trainers were familiar with Miller and Moyers' (2006) eight stages of learning MI.

Additionally, Schumacher and colleagues' (2012) survey of 36 experienced MI trainers (in and out of MINT) concerned the optimal format, length, and content of MI trainings. The survey demonstrated wide variability of MI teacher opinions 
about which MI exercises and concepts were most important to teach (Schumacher et al., 2012). This creates dilemmas for consumers of MI teaching and further indicates a need to track what type of content is taught among MI trainers. Doing so may eventually allow us to establish links between course content, skills acquisition, and ultimate client outcomes.

The studies by Madson et al. (2012) and Schumacher et al. (2012) explore training processes related to the learning and teaching of MI, respectively. Although both studies look at the types of exercises used by trainers for skill building, among other elements, our study attends more to trainer pedagogy rather than specific exercises and content. Consequently, our study offers the MI learning/training literature novel constructs that previously have been mentioned only in the oral history of MINT.

Summary of research on MI training, and purpose of study. Limited research exists on what makes a "good" (enough) MI trainer/teacher, nor is there evidence that any particular teaching method is superior to another (Madson, Lane, \& Noble, 2012). There is disagreement about what type of follow up, supervision (e.g., teleconference supervision), and coaching (e.g., audio recording) might be most effective (Smith et al., 2012). One barrier to conducting such research is the lack of reliable and valid scales measuring MI teaching quality.

The purpose of this study was to develop and test a measure of MI teaching quality that, based on prior research, anticipated five dimensions of MI teaching.

\section{Methods}

\section{Procedure}

Human subjects approval for this study was obtained from the institutional review boards of all institutions where students contributed data to this study. The initial item pool was generated by expert consensus by the authors, all of whom are members of MINT. The authors attended multiple MINT-sponsored conferences focusing on MI teaching strategies, and they also served on subcommittees developing guidelines for professional development of MI trainers within MINT. The items generated were meant to measure dimensions of teaching generally considered important by MINT members, including: modeling the global spirit of MI, covering content areas considered important to the intervention, refraining from using heavy-handed approaches to convince trainees to use MI (i.e., supporting students' autonomy to decide whether or not to use MI), using interactive teaching strategies, and conveying the importance of ongoing training and professional development to students. The authors made a priori hypotheses about factors (i.e., measure subscales) that would emerge to represent these dimensions of teaching. The final item pool included 44 potential items for inclusion on the scale. Survey items asked to what extent participants agreed or disagreed $(1=$ strongly disagree, $3=$ neither agree 
nor disagree, 5 = strongly agree) with statements about their instructor's teaching. (e.g., My instructor provided opportunities to practice MI skills).

In addition to responding to items in the item pool, study participants responded to questions about their demographic characteristics (e.g., age [in years], race, gender), level of education, prior training in MI (in hours), favorability toward using role plays $(1$ = extremely dislike, 5 = extremely enjoy), and level of anxiety about recording mock interviews ( $1=$ no anxiety, $5=$ extreme anxiety).

After generating the item pool, students enrolled in the authors' classes between August 2013 and May $2014(N=297)$ were invited to participate in this study. Specifically, students were enrolled in a large social work undergraduate and graduate program in the western United States $(n=194)$, a Master of Social Work program in a large university in the Midwestern U.S. $(n=36)$, a Master of Social Work program in the U.S. Pacific Northwest $(n=26)$, and in a Bachelor of Social Work program in a New Zealand university $(n=41)$. All students completed the survey after finishing MI training but before their grades were posted. Prior to completing the survey, students read a consent letter explaining the purpose, risks, and benefits of the study. They were informed that participation was voluntary, and they could elect to not participate by simply leaving the forms blank. Because students completed the surveys anonymously and no identifying information linked surveys to other student information (i.e., routine classroom evaluations, GPA, MI performance on class assignments), we did not collect written informed consent. Students were not compensated for participation in this study.

Data were nested within 10 different classrooms taught by 4 different instructors. The courses varied in length of exposure to MI (two 16-week courses, eight 4-week courses). The instructors were MINT members for an average of 8.25 years (Range: 4-13). On average, the instructors taught MI in college courses 4.0 times $(S D=3.68)$ prior to teaching the first class in which they contributed data to this study.

\section{Data Analysis}

Data were analyzed with SPSS Version 21 (IBM Corp., 2012) using the alpha method with oblique rotation (Kaiser \& Coffrey, 1965). Because this form of factor analysis is an exploratory approach, we used several criteria for selecting a factor solution: (a) including only items that loaded onto a factor at .40 or higher, (b) including factors with eigenvalues higher than 1.0, (c) visually inspecting the scree plot for a steep drop in the percentage of variance explained by increasingly more factors, and (d) the absence of cross-loading of items onto multiple factors (McDermeit, Funk, Foss, \& Dennis, 2000). These "stopping rule" criteria are all used to encourage researchers to select parsimonious factor solutions. One item was dropped from the analysis due to a large amount of missing data. That is, the item-My instructor worked collaboratively with other instructors (if applicable)-did not apply to the 
classes in this analysis, which were taught by individual instructors. The factor analysis included the other 43 items in the initial item pool.

To determine if results were robust to extraction method, we used two additional extraction methods: principal axis factoring and unweighted least squares. We used oblique rotation in all models. Additionally, sensitivity analyses were conducted to determine if the factor structure would change by only analyzing a subset of items that seemed more specific to training on MI versus general pedagogy. Results were robust to both extraction methods and whether we used the full versus MI-specific subset of items. Thus, we present findings only for the pattern matrix of the alpha extraction method. Full results for all models (and structure matrices) are easily retrievable in Open Science Framework (https://osf.io/6dhmw/).

\section{Results}

On average, students were 27.9 years old $(S D=8.0)$ and were predominately female (86\%). Participants were from diverse racial backgrounds, including White (32.2\%), Hispanic (25.2\%), New Zealander/European (11.2\%), Asian (9.8\%), African American (5.6\%), multiracial (5.2\%), or other (10.8\%). The U.S. students were mostly undergraduate $(61.9 \%)$ versus graduate $(29.6 \%)$ students. The New Zealand students were all undergraduate students (100\%), as a Bachelor of Social Work degree is a terminal degree in the New Zealand educational system. Slightly more than half of the participants (56.7\%) reported having some human-services experience, reporting an average of $3.3(S D=3.8$ ) years of such experience. The median number of hours of prior MI training experience was zero $(M=3.2, S D=10.0)$. Those individuals $(19.5 \%, n=55)$ who had reported receiving prior MI training endorsed receiving the following types of instruction: taking an MI course (9.2\%), receiving clinical supervision on MI (3.4\%), having an informational training on MI (5.1\%), reading the MI book (7.9\%), reading any book or articles on MI (12.7\%), watching an instructional video (7.9\%), having their MI performance taped and critiqued $(2.4 \%)$, or some other instruction in MI (3.8\%). Students, on average, held favorable views toward the use of role plays as an instructional technique, reporting that they "enjoyed" the use of role plays $(M=4.00, S D=.79 ; 1=$ extremely dislike, $5=$ extremely enjoy). The sample's mean score for recording anxiety $(M=2.5, S D=1.0)$ fell between the response choices indicative of "a little anxiety" (2) and "moderate anxiety" (3).

\section{Findings}

The data did not support our a priori five-factor model that would include subscales for MI content coverage, interactivity, encouragement of ongoing training, trainee autonomy violation, and modeling MI skills during training. Instead, the two-factor (Kaiser-Meyer-Olkin $=.897$; Bartlett's Test: $\chi^{2}=4387.2, \mathrm{df}=861, p<.001$ ) and three-factor (Kaiser-Meyer-Olkin $=.897$; Bartlett's Test: $\chi^{2}=4387.2, d f=861$, 
$p<.001$ ) models met most of our a priori selection criteria. We ultimately selected the two-factor model due to the presence of cross-loading items in the three-factor solution, the inability to easily interpret the third factor based on our theoretical model of important dimensions of MI teaching, and a nominal increase in the percent of variance explained by the three-factor model (3.9\% additional percent of variance explained). Tables 2 and 3 present factor loadings and item means for the 43 items in the initial item pool; the tables also indicate what factor we originally hypothesized each item would load onto in our a priori five-factor model. A summary of the three-factor solution and the list of items with weak loadings are available on our Open Science Framework page.

Items loading onto the first factor were conceptualized a priori as important teaching strategies, so this scale was labeled the MI-Consistent Teaching Scale (MICTS, 28 items, $\alpha=.92$, Range: 28-140). Items with the highest loadings on this scale included "Was affirming," "Was a good listener," and "Debriefed training exercises when they were done." All three loaded onto the MICTS at .71. Across all classrooms, the average score in this sample was $127.7(S D=10.4)$. The distribution was left skewed, indicating that students reported MI-consistent teaching practices were common in these classrooms. In contrast, items loading onto the second factor were those intentionally developed to measure teaching strategies that are contraindicated by MI trainers in MINT. We called this subscale the MI-Inconsistent Teaching Scale (MIITS; 7 items, $\alpha=.73$, Range: 7-35). The most highly loading items for the MIITS included "Was quite critical of my mistakes" (.67), "Told us MI is a way to get people to do things they don't want to do" (.61), and "Tried to persuade us to use MI, even if we had doubts" (.53). On this scale, higher scores indicate using teaching practices that are typically contraindicated. For MIITS, the grand mean across classrooms was $22.3(S D=4.7)$. The correlation between these two factors was low $(r=.11$, $p=.07)$.

Supplemental Analyses. Table 4 presents descriptive information and correlations between select participant characteristics and EMIT subscale scores. Age was correlated with hours of previous MI training $(r=.16, p<.05)$ and negatively correlated with anxiety regarding recording anxiety $(r=-.13, p<.05)$. Recording anxiety was negatively correlated with role-play attitude $(r=-.19, p<.01)$. Role-play favorability was positively associated with the MICTS $(r=.28, p<.01)$, indicating that those who enjoy role plays viewed their instructors as using more MI-consistent teaching methods. Additionally, two background variables were associated with the EMIT's subscales. First, age was positively associated with the MIITS $(r=.19, p<.01)$, indicating that older students rated their instructors as using more MI-inconsistent teaching methods. Second, students from White racial backgrounds $(1=$ White, $0=$ multiracial or any race other than White) reported both lower MICTS scores $(M=125.4$ vs. 130.1 for non-White students, $p<.001)$ and higher MIITS scores $(M=23.7$ vs. 21.3 for non-White students, $p<.001)$. Thus, students from White 
Table 2

Factor Loadings, Mean Scores for Items, and Originally Hypothesized Constructs for MI-Consistent Teaching Subscale

\begin{tabular}{|c|c|c|c|c|}
\hline Item & MICTS & MIITS & Mean (SD) & Scale \\
\hline Debriefed training exercises when they were over & 0.71 & 0.17 & $4.6(.68)$ & I \\
\hline Seemed to be well-organized & 0.66 & 0.03 & $4.8(.51)$ & - \\
\hline Provided useful training activities & 0.64 & -0.01 & $4.7(.53)$ & I \\
\hline $\begin{array}{l}\text { Gave clear guidelines for providing feedback to } \\
\text { each other }\end{array}$ & 0.60 & -0.23 & $4.5(.75)$ & I \\
\hline Created a safe environment for real/role plays & 0.64 & 0.08 & $4.8(.48)$ & I \\
\hline $\begin{array}{l}\text { Gave clear directions for all exercises/activities } \\
\text { before we started }\end{array}$ & 0.59 & -0.03 & $4.5(.67)$ & - \\
\hline $\begin{array}{l}\text { Gave us enough time to practice skills, in the } \\
\text { length of time we had }\end{array}$ & 0.59 & 0.01 & $4.5(.75)$ & I \\
\hline Provided opportunities to practice MI skills & 0.58 & 0.00 & $4.8(.41)$ & I \\
\hline Identified our strengths when doing real/role plays & 0.50 & -0.15 & $4.3(.88)$ & I \\
\hline Made good use of multimedia & 0.53 & -0.05 & $4.3(.79)$ & I \\
\hline Used a variety of teaching methods & 0.49 & -0.08 & $4.3(.79)$ & I \\
\hline Provided ample opportunities for Q and A & 0.51 & 0.18 & $4.6(.67)$ & I \\
\hline Was affirming & 0.71 & 0.09 & $4.5(.59)$ & M \\
\hline Was a good listener & 0.71 & 0.12 & $4.7(.55)$ & M \\
\hline $\begin{array}{l}\text { Demonstrated the spirit of MI in their teaching } \\
\text { methods }\end{array}$ & 0.57 & 0.06 & $4.8(.40)$ & M \\
\hline Evoked our thoughts and ideas often & 0.58 & 0.10 & $4.6(.62)$ & M \\
\hline Modeled OARS skills in all of their interactions & 0.57 & 0.01 & $4.6(.66)$ & M \\
\hline Overall, used a guiding style of communication & 0.54 & -0.19 & $4.5(.68)$ & M \\
\hline Demonstrated MI in his/her teaching methods & 0.57 & 0.06 & $4.8(.44)$ & M \\
\hline $\begin{array}{l}\text { Used reflections in responding to student } \\
\text { comments }\end{array}$ & 0.42 & 0.13 & $4.8(.52)$ & M \\
\hline Gave lots of examples of eliciting change talk & 0.63 & -0.04 & $4.5(.67)$ & $\mathrm{C}$ \\
\hline $\begin{array}{l}\text { Helped us recognize when to transition in the } \\
\text { four MI processes based on what we hear } \\
\text { from clients }\end{array}$ & 0.43 & -0.01 & $4.2(.84)$ & $\mathrm{C}$ \\
\hline $\begin{array}{l}\text { Provided demonstrations of MI (video, real/ } \\
\text { role plays) }\end{array}$ & 0.57 & 0.11 & $4.8(.46)$ & $\mathrm{C}$ \\
\hline Provided information about the MI spirit & 0.55 & -0.05 & $4.8(.46)$ & $\mathrm{C}$ \\
\hline Covered the four processes of MI & 0.43 & -0.01 & $4.7(.59)$ & $\mathrm{C}$ \\
\hline $\begin{array}{l}\text { Described the difference between "sustain talk" } \\
\text { and "discord" }\end{array}$ & 0.42 & -0.04 & $4.5(.81)$ & $\mathrm{C}$ \\
\hline Described some of the limitations of MI & 0.39 & -0.20 & $3.9(.89)$ & $\mathrm{C}$ \\
\hline $\begin{array}{l}\text { Provided information about ways to keep } \\
\text { learning MI }\end{array}$ & 0.46 & -0.27 & $4.3(.90)$ & OT \\
\hline
\end{tabular}

Note. $\mathrm{MI}=$ motivational interviewing. MICTS $=$ factor loadings for the Motivational Interviewing Consistent Teaching Scale. MIITS = factor loadings for the Motivational Interviewing Inconsistent Teaching Scale. Scale: a priori hypothesized subscale in proposed five-factor model ( $\mathrm{I}=$ interactive training, $\mathrm{M}=$ modeling $\mathrm{MI}$ skills, $\mathrm{C}=\mathrm{MI}$ content coverage, $\mathrm{OT}=$ emphasizing ongoing training, $-=$ no a priori hypothesis). $S D=$ standard deviation. 
Table 3

Factor Loadings, Item Means, and Originally Hypothesized Construct for MI-Inconsistent

Teaching Subscale

\begin{tabular}{|c|c|c|c|c|}
\hline Item & MICTS & MIITS & Mean $(S D)$ & Scale \\
\hline Was quite critical of my MI practice mistakes & 0.04 & 0.67 & $2.2(1.4)$ & - \\
\hline $\begin{array}{l}\text { Told us that MI is a way to get people to do things } \\
\text { they don't want to do }\end{array}$ & 0.10 & 0.61 & $1.8(1.2)$ & $\mathrm{C}$ \\
\hline Tried to talk the students into liking MI & 0.08 & 0.51 & $2.7(1.3)$ & AV \\
\hline Tried to persuade us to use MI, even if we had doubts & -0.08 & 0.53 & $3.9(1.3)$ & AV \\
\hline $\begin{array}{l}\text { Told us that MI is a set of microskills that most } \\
\text { people use already }\end{array}$ & -0.10 & 0.47 & $3.4(1.2)$ & OT \\
\hline $\begin{array}{l}\text { Encouraged us to get ongoing supervision } \\
\text { in MI (reversed) }\end{array}$ & 0.24 & -0.49 & $2.4(1.2)$ & OT \\
\hline Said that MI can be applied to about any problem & -0.03 & 0.45 & $3.4(1.2)$ & - \\
\hline
\end{tabular}

Note. $\mathrm{MI}=$ motivational interviewing. MICTS $=$ factor loadings for the Motivational Interviewing Consistent Teaching Scale. MIITS = factor loadings for the Motivational Interviewing Inconsistent Teaching Scale. Scale $=$ a priori hypothesized subscale in proposed five-factor model $(\mathrm{C}=\mathrm{MI}$ content coverage, $\mathrm{AV}=$ trainee autonomy violation, $\mathrm{OT}=$ emphasizing ongoing training, $-=$ no a priori hypothesis). $S D=$ standard deviation.

Table 4

Correlations between MICTS, MIITS, and Selected Participant Characteristics

\begin{tabular}{lcccccc}
\hline & 1. & 2. & 3. & 4. & 5. & 6. \\
\hline 1. MICTS & 1.0 & & & & & \\
2. MIITS & -.107 & 1.0 & & & & \\
3. Age (in years) & -.065 & $.189^{* *}$ & 1.0 & & & \\
4. Hours of MI Training & -.032 & .091 & $.160^{*}$ & 1.0 & & \\
5. Recording Anxiety & -.004 & -.109 & $-.131^{*}$ & -.091 & 1.0 & \\
6. Role Play Favorability & $.279^{* *}$ & -.047 & -.080 & .011 & $.191^{* *}$ & 1.0 \\
\hline & & & & & & \\
Means & 127.8 & 22.3 & 27.9 & 3.2 & 2.5 & 4.0 \\
(SD) & 10.4 & 4.7 & 8.0 & 10.1 & 1.0 & 0.8 \\
& & & & & & \\
\hline
\end{tabular}

Note. MICTS $=$ Motivational Interviewing Consistent Teaching Scale. MIITS $=$ Motivational Interviewing Inconsistent Teaching Scale. $\mathrm{MI}=$ motivational interviewing. $S D=$ standard deviation.

${ }^{*} p<.05$.

${ }^{* *} p<.01$.

This content downloaded from 131.252.181.102 on April 19, 2018 14:00:45 PM

All use subject to University of Chicago Press Terms and Conditions (http://www.journals.uchicago.edu/t-and-c). 
racial backgrounds rated their teachers as less MI consistent (MICTS) and more MI inconsistent (MIITS). Gender was not significantly associated with either MIITS or MICTS scores.

\section{Discussion}

Social work programs are increasingly including content on MI, and there currently is no validated measure of teaching competency for MI instructors. Therefore, this study takes an important first step in the direction of conceptualizing and measuring MI teaching quality. Study findings indicate that instead of five proposed theory-based subscales, two dimensions captured poorer and more optimal MI training practices.

There are two potential reasons for why only two dimensions of MI teaching emerged. First, the instructors in this study were all experienced teachers and had been involved with MINT for several years. The proposed factors may simply not have been detectable in this analysis due to range restriction in scores across items (i.e., positive skew), which resulted from using experienced instructors. That is, instructors had high means on most items loading onto the MI-Consistent factor, and low means on the items loading onto the MI-Inconsistent factor (see tables 2 and 3). Such range restriction could have suppressed the emergence of different factors, especially for proposed factors thought to represent best practices in MI training. Second, it may be that some of the facets of training thought to be important in teaching MI (i.e., modeling MI, providing an interactive training) are simply not viewed as conceptually distinct by students. However, it strikes us as unusual that some of the items meant to simply measure content coverage (i.e., "My instructor described the four processes of MI") load onto the same factor as measuring attempts to model MI behaviors in a parallel process during teaching (i.e., "My instructor evoked our thoughts and ideas often"). This implies that future research should replicate this study using trainers of varying levels of experience. If MI teaching practices are more multidimensional than found here, we would expect inexperienced instructors to be higher on some scales and lower on others. For example, content coverage, which has to do with exposure to various topics in MI, seems like a less advanced teaching skill than modeling MI. The latter requires instructors to think on their feet when responding to student questions and to generate MI-consistent responses, such as complex reflections (e.g., you are unsure if MI is going to work in your workplace, and you see no benefit at all of continuing to learn it), to students in real time.

Regarding construct validity, it is encouraging that scores of experienced trainers were low on the MI-Inconsistent scale and high on MI-Consistent scale. However, we note that some items meant to measure violating trainee autonomy, such as "My instructor tried to persuade us to use MI, even if we had doubts" $(M=3.9, S D=1.3)$ did not have mean scores as low as we would have expected for these trainers. That 
is, if instructors were supporting student autonomy, we'd expect very low item means, reflecting disagreement with these statements. We believe that these findings may be due to university professors seeing themselves as being in the dual role of promoting the use of evidence-based practices while simultaneously being encouraged by MINT to model autonomy respect with their trainees. Thus, presentation of information (i.e., reviewing the vast literature on MI effectiveness as a deliberate persuasive technique), which is technically contraindicated in the MI intervention as a persuasion method, may be somewhat unavoidable in teaching. However, we'd expect instructors scoring high on supporting student autonomy to say or write things to students like, "If you decide to continue learning MI, you recognize the need to improve your ability to focus on being present with your clients." This study did not use observational measures of instructors' behaviors to permit us to know the extent of use of these types of statements. Future research may compare student self-reported EMIT scores to observational measures of instructors' MI teaching proficiency to further establish the construct validity of the EMIT.

Additional preliminary evidence for construct validity arose from the finding that role-play favorability was positively correlated with MICTS scores. Thus, those students who liked to role play rated their instructors higher on the MICTS. Roleplay favorability should be positively associated with the MICTS $(r=.279)$, as many MICTS items pertain directly to role playing.

These preliminary analyses also revealed that age and gender were not significantly associated with MIITS or MICTS scores. Student racial background, however, was significantly associated with scale scores, with White students reporting lower MICTS and higher MIITS scores. We caution readers to not overinterpret this finding, as these preliminary bivariate analyses need to be replicated in hierarchical linear modeling studies that disassociate classroom and instructor effects from student background. Student race here was largely confounded with one instructor's classrooms, and explaining classroom factors that influence these scores goes beyond the scope of this article. Future research is needed on what classroom processes and student backgrounds influence MIITS and MICTS scores.

\section{Limitations}

Although our study sampled a reasonable number of participants for an exploratory factor analysis (Comrey \& Lee, 1992), this study's findings should be interpreted cautiously in light of its limitations. First, most students in this study were undergraduates, so additional research is needed with social work master's degree students. Additionally, these findings may not generalize to shorter MI modules that may be used in some curricula. That is, all but two classrooms included in this study provided approximately 45 classroom hours of MI instruction. However, this also is a strength of this measure, in that we'd expect length, content, and extent to which the training is hands-on to indicate both the amount of exposure and quality 
of teaching. Administering this instrument to individuals receiving shorter modules could help establish discriminant validity for this instrument. Additionally, although the authors are all experienced MI trainers, it is possible that the item pool may need to be expanded to achieve adequate coverage of various constructs that were hypothesized to be important dimensions of MI teaching. Similarly, some items may measure more general teaching processes - not necessarily those specific to MI (e.g., "My instructor seemed to be well-organized"). Although the inclusion of these generic teaching items may do little to clarify unique teaching processes for MI, their inclusion may facilitate future studies of discriminant validity. For example, if this instrument was administered to students where a practice other than MI was taught, the instrument may have more face validity to students if it included both MI-specific and general-teaching items. We would expect the scores on the MI-content items to be lower in such a study, but it is possible that general teaching could be rated similarly for other classes where interactive role plays are used. Lastly, although this study produced an easy-to-administer survey for MI teaching, our study was unable to link these data to actual training outcomes for participants. Students and practitioners are increasingly being evaluated after trainings by collecting audiotaped role plays that are coded by reliable and valid observational measures of MI performance (Moyers et al., 2010). Future research is needed that links individuals' scores on this measure of teacher competency in MI to separate measures of trainee MI performance or global course satisfaction.

\section{Conclusions}

Notwithstanding this study's limitations, the major contribution of this study is the initial development of internally consistent (i.e., factorial validity) measures of MI-Consistent and MI-Inconsistent teaching practices. As MI enjoys empirical support for use across many health-behavior problems, and there is increasing demand for MI training in schools of social work and other venues, it is imperative that we examine the assumptions of MI trainers as to what makes a good training. Future research should examine the links between classroom content, student self-reported evaluation of MI teaching, student skill acquisition in MI, and client outcomes.

\section{Author Notes}

Douglas Smith, $\mathrm{PhD}$, is an associate professor of social work at the University of Illinois at Urbana-Champaign.

Melinda Hohman, PhD, is professor and director, School of Social Work, San Diego State University.

Stéphanie Wahab, PhD, is a professor of social work at Portland State University.

Trevor Manthey, $\mathrm{PhD}$, is a senior research associate at the George Washington University Center for Rehabilitation, Counseling, Research and Education. 
Correspondence regarding this article should be directed to Douglas Smith, 1010 West Nevada Street, Urbana, IL 61821 or via e-mail to smithdc@illinois.edu

\section{Acknowledgments}

A previous version of this article was presented at the 2014 Motivational Interviewing Network of Trainers Forum (MINT Forum) in Atlanta, GA. Support for the development of this article came from SAMHSA (\#TI-026046; PI: Smith). The opinions in this article, however, are those of the authors and do not reflect official positions of the federal government.

\section{References}

Baer, J., Rosengren, D., Dunn, C., Wells, E., Ogle, R., \& Hartzler, B. (2004). An evaluation of workshop training in motivational interviewing for addiction and mental health clinicians. Drug and Alcohol Dependence, 73, 99-106. http/dx//doi:10.1016/j.drugalcdep.2003.10.001

Bennett, G., Moore, J., Vaughan, T., Rouse, L., Gibbons, J., Thomas, P., . . Gower, P. (2007). Strengthening motivational interviewing skills following initial training: A randomized trial of workplace-based reflective practice, Addictive Behaviors, 32, 2963-2975. doi:10 .1016/j.addbeh.2007.06.013

Comrey, A. L., \& Lee, H. B. (1992). A first course in factor analysis. Hillsdale, NJ: Erlbaum.

Council on Social Work Education. (2015). 2015 educational policy and accreditation standards for baccalaureate and master's social work programs. Retrieved from http://www.cswe.org/File .aspx?id $=81660$

Decker, S. E., \& Martino, S. (2013). Unintended effects of training on clinicians' interest, confidence, and commitment in using motivational interviewing. Drug and Alcohol Dependence, 132, 681-687. http://dx.doi.org/10.1016/j.drugalcdep.2013.04.022

Forsberg, L., Ernst, D., \& Farbring, C. A. (2011). Learning motivational interviewing in a real life setting: A randomized controlled trial in the Swedish Prison Service. Criminal Behavior and Mental Health, 21(3), 177-188. doi:10.1002/cbm.792

Forsberg, L., Forsberg, L. G., Lindqvist, H., \& Helgason, A. R. (2010). Clinician acquisition and retention of motivational interviewing skills: A two and a half year exploratory study. Substance Abuse Treatment, Prevention and Policy, 5(8), 1-14. doi:10.1186/1747-597X-5-8)

Gifford, E. V., Tavakoli, S., Weingardt, K. R., Finney, J. W., Pierson, H. M., Rosen, C. S., . . Curran, G. M. (2012). How do components of evidence-based psychological treatment cluster in practice?: A survey and cluster analysis. $\underline{\text { Journal of Substance Abuse Treatment, }}$ 42(1), 45-55. http://dx.doi.org/10.1016/j.jsat.2011.07.008

Heaven, C., Clegg, J., \& Maguire, P. (2006). Transfer of communication skills from workshop to workplace: The impact of clinical supervision. Patient Education and Counseling, 60(3), 312-325. http://dx.doi.org/10.1016/j.pec.2005.08.008

Hohman, M. (2012). Motivational interviewing in social work practice. New York, NY: Guilford Press.

Hohman, M., Pierce, P., \& Barnett, E. (2015). Motivational interviewing: An evidence-based practice to improve student practice skills. Journal of Social Work Education, 51, 287-297. doi:10.1080/10437797.2015.1012925

IBM Corp. (2012). IBM SPSS Statistics for Windows, Version 21.0 [Software]. Armonk, NY: IBM Corp.

Kaiser, H. F., \& Coffrey, J. (1965). Alpha factor analysis, Psychometrika, 30, 1-14. doi:10.1007 /BF02289743 
Madson, M. B., Campbell, T., Barrett, D. E., Brondino, M. J., \& Melchert, T. P. (2005). Development of the motivational interviewing supervision and training scale. Psychology of Addictive Behaviors, 19(3), 303-310. http://dx.doi.org/10.1037/0893-164X.19.3.303

Madson, M. B., Lane, C., \& Noble, J. J. (2012). Delivering quality motivational interviewing training: A survey of motivational interviewing trainers. Motivational Interviewing, Training, Research, Implementation, and Practice (MITRIP), 1(1), 16-24. http://dx.doi.org/10.5195/mitrip .2012 .8

Madson, M., Loignon, A., \& Lance, C. (2009). Training in motivational interviewing: A systematic review. Lournal of Substance Abuse Treatment, 36, 101-109. http://dx.doi.org/10.1016/j .jsat.2008.05.005

Magill, M., Gaume, J., Apodaca, T. R., Walthers, J., Mastroleo, N. R., Borsari, B., \& Longabaugh, R. (2014). The technical hypothesis of motivational interviewing: A meta-analysis of MI's key causal model. Journal of Consulting and Clinical Psychology, 82(6), 973-983. http://dx.doi .org/10.1037/a0036833

Manthey, T., Jackson, C., \& Evans-Brown, P. (2011). Motivational interviewing and vocational rehabilitation: A review with suggestions for administrators and counselors. Journal of Applied Rehabilitation Counseling, 42(1), 3-14.

Manthey, T. J., Knowles, B., Asher, D., \& Wahab, S. (2011). Strengths-based practice and motivational interviewing. Advances in Social Work, 12, 126-151. https://journals.iupui.edu/index .php/advancesinsocialwork/article/view/959/1866

McDermeit, M., Funk, R., Foss, M., \& Dennis, M. L. (2000). Exploratory Factor Analysis with alpha method and varimax rotation. Bloomington, IL: Chestnut Health Systems. Retrieved from http:/ www.gaincc.org/_data/files/Psychometrics_and_Publications/Resources/Training_ Memos /Factora.pdf

Miller, W. R., Forcehimes, A. A., \& Zweben, A. (2011). Treating addiction: A guide for professionals. New York, NY: Guilford Press.

Miller, W. R., \& Mount, K. A. (2001). A small study of training in motivational interviewing: Does one workshop change clinician and client behavior? Behavior and Cognitive Psychotherapy, 29, 457-471. http://dx.doi.org/10.1017/S1352465801004064

Miller, W. R., \& Moyers, T. B. (2006). Eight stages in learning motivational interviewing. Journal of Teaching in the Addictions, 5(1), 3-17. doi:10.1300/J188v05n01_02

Miller, W. R., \& Rollnick, S. (2002). Motivational interviewing: Preparing people for change. (2nd Ed.). New York, NY: Guilford Press.

Miller, W. R., \& Rollnick, S. (2009). Ten things that motivational interviewing is not. Behavioral and Cognitive Psychotherapy, 37, 129-140. http://dx.doi.org/10.1017/S1352465809005128

Miller, W. R., \& Rollnick, S. (2013). Motivational interviewing: Helping people change (3rd Ed.). New York, NY: Guilford Press.

Miller, W. R., Yahne, C. E., Moyers, T. B., Martinez, J., \& Pirritano, M. (2004). A randomized trial of methods to help clinicians learn motivational interviewing, Journal of Consulting and Clinical Psychology, 72, 1050-1062. http://dx.doi.org/10.1037/0022-006X.72.6.1050

MINT Forum (2014, October). Plenary discussion on trainer certification. Motivational Interviewing Network of Trainers Forum, Atlanta, GA.

Mitcheson, L., Bhavsar, K., \& McCambridge, J. (2009). Randomized trial of training and supervision in motivational interviewing with adolescent drug treatment practitioners. Iournal of Substance Abuse Treatment, 37, 73-78. http://dx.doi.org/10.1016/j.jsat.2008.11.001

Moyers, T., Manuel, J., Wilson, P., Hendrickson, S., Talcott, W., \& Durand, P. (2008). A randomized trial investigating training in motivational interviewing for behavioral health 
providers. Behavioral and Cognitive Psychotherapy, 36, 149-162. http://dx.doi.org/10.1017 IS1352465807004055

Moyers, T. B., Martin, T., Manual, J. K., Miller, W. R., \& Ernst, D. (2010). Revised global scales: Motivational Interviewing Treatment Integrity 3.1.1 (MITI 3.1.1). Albuquerque, NM: University of New Mexico Center on Alcoholism, Substance Abuse and Addictions (CASAA).

Rosengren, D. B. (2009). Building motivational interviewing skills: A practitioner workbook. New York, NY: Guilford Press.

Roten, Y., Zimmermann, G., Ortega, D., \& Despland, J. N. (2013). Meta-analysis of the effects of MI training on clinicians' behavior. Iournal of Substance Abuse Treatment, 45(2), 155-162. http://dx.doi.org/10.1016/j.jsat.2013.02.006

Santa Ana, E. J., Martino, S., Ball, S. A., Nich, C., Frankforter, T. L., \& Carroll, K. M. (2008). What is usual about "treatment-as-usual"? Data from two multisite effectiveness trials. Iournal of Substance Abuse Treatment, 35(4), 369-379. http://dx.doi.org/10.1016/j.jsat.2008 .01 .003

Schumacher, J. A., Coffey, S. F., Walitzer, K. S., Burke, R. S., Williams, D. C., Norquist, G., \& Elkin, T. D. (2012). Guidance for new motivational interviewing trainers when training 22 addiction professionals: Findings from a survey of experienced trainers. Motivational Interviewing, Training, Research, Implementation, and Practice (MITRIP), 1(1), 1-15.

Smith, D. C., (2012). Jacquelines of all trades or masters of some: Negative implications of focusing on common factors. Social Work, 57(3), 283-287. doi:10.1093/sw/sws038

Smith, J. L., Carpenter, K. M., Amrhein, P. C., Brooks, A. C., Levin, D., Schreiber, E. A., Nunes, E. V. (2012). Training substance abuse clinicians in motivational interviewing using live supervision via teleconferencing. Iournal of Consulting and Clinical Psychology, 80(3), 450454. http://dx.doi.org/10.1037/a0028176

Söderlund, L. L., Madsen, M. B., Rubak, S., \& Nilsen, P. (2011). A systematic review of motivational interviewing training for general health care practitioners. Patient Education and Counseling, 84(1), 16-26. http://dx.doi.org/10.1016/j.pec.2010.06.025

Wahab, S. (2005). Motivational interviewing and social work practice. Iournal of Social Work, 5 (1), 45-60. doi:10.1177/1468017305051365

Wain, M. R., Kutner, B. A., Smith, J. L., Carpenter, K. M., Hu, M. C., Amrhein, P. C., \& Nunes, E. V. (2015). Self-report after randomly assigned supervision does not predict ability to practice motivational interviewing. Journal of Substance Abuse Treatment, 57, 96-101. http://dx.doi .org/10.1016/j.jsat.2015.04.006

Walters, S. T., Matson, S. A., Baer, J. S., \& Ziedonis, D. M. (2005). Effectiveness of workshop training for psychosocial addiction treatments: A systematic review. Iournal of Substance Abuse Treatment, 29, 283-293. http://dx.doi.org/10.1016/j.jsat.2005.08.006

Wells, H., Jones, A., \& Jones, S. C. (2014). Teaching reluctant students: Using the principles and techniques of motivational interviewing to foster better student-teacher interactions. Innovations in Education and Teaching International, 51, 175-184. http://dx.doi.org/10.1080 /14703297.2013.778066

Manuscript submitted: March 29, 2016

First revision submitted: July 8, 2016

Second revision submitted: July 19, 2016

Accepted: July 26, 2016

Electronically published: January 26, 2017 